\title{
Regimen complexity and medication nonadherence in elderly patients
}

\author{
Andrea Corsonello' \\ Claudio Pedone ${ }^{3}$ \\ Fabrizia Lattanzio² \\ Maria Lucchetti ${ }^{2}$ \\ Sabrina Garasto' \\ Claudia Carbone' \\ Cosetta Greco 2 \\ Paolo Fabbietti ${ }^{2}$ \\ Raffaele Antonelli Incalzi ${ }^{3,4}$ \\ 'Istituto Nazionale di Ricovero e \\ Cura per Anziani (INRCA), Cosenza; \\ ${ }^{2}$ Ancona, Italy; ${ }^{3}$ Cattedra di Geriatria, \\ Università Campus BioMedico, Rome, \\ Italy; ${ }^{4}$ Fondazione San Raffaele, \\ Cittadella della Carità, Taranto, Italy
}

Correspondence: Andrea Corsonello Viale della Resistenza, Pal. Alfa Scala H, I-87036 Rende (CS), Italy

$\mathrm{Tel}+390984461872$

Fax +390984461872

Email andrea_corsonello@tin.it
Objective: To assess whether the number of daily administrations of individual drugs, as a measure of regimen complexity, contributes to the profile of an elderly patient who adheres poorly to the prescribed therapy.

Population: Six hundred ninety patients over 64 years who were consecutively admitted to 11 acute medical care and three long term/rehabilitation wards in Italy.

Main outcome measure: Self-reported adherence to drugs taken at home before admission was measured by a single question assessment for each listed drug supplemented with a latter question about the circumstances of the missed administration. For cognitively impaired patients the question was put to patients' relatives or caregivers.

Methods: A structured multidimensional assessment was performed to identify nonadherence and its potential correlates. Correlates of nonadherence were identified by multivariable logistic regression.

Results: We recorded 44 cases $(6.4 \%)$ of nonadherence to at least one drug. Being assisted by foreign caregivers (OR 2.17; 95\% CI 1.02-4.63) and the use of at least one multiple daily dosing drug (OR 2.99; 95\% CI 1.24-7.17) were significant independent correlates of medication nonadherence, while age, selected indexes of frailty and the cumulative number of prescribed drugs were not.

Conclusion: Regimen complexity and type of assistance are independent correlates of medication nonadherence.

Keywords: elderly, medication adherence, regimen complexity

\section{Introduction}

Poor adherence to the prescribed therapy has been repeatedly reported to be highly prevalent in different settings and populations..$^{1-5}$ It largely contributes to explain why control of hypertension or of diabetes is frequently unsatisfactory and, thus, it has major health care and economic implications. ${ }^{3,5-7}$ Accordingly, many authors have tried to profile the noncompliant patient in order to predispose preventive interventions. ${ }^{5,8-14}$ Results vary with the studied population and the method used. For instance, younger patients are more likely to be noncompliant in diabetic, ${ }^{5}$ but not in hypertensive populations. ${ }^{8,11}$ Overall, elderly and female gender are recurring nonmodifiable correlates of poor compliance, ${ }^{8,15}$ although discordant results have been reported..$^{9,10}$ Lower educational level, less affluent economic status, cognitive/physical impairment and some diseases such as chronic renal failure are commonly reported poorly modifiable correlates of nonadherence. ${ }^{8,10,12,16,17}$ On the other hand, regimen complexity, as reflected by the number of prescribed drugs, represents an important and to some extent modifiable correlate of the outcome. ${ }^{18,19}$ Thus, attempts at reducing the number of prescribed drugs, also to prevent adverse drug reactions, are highly recommendable, especially in elderly patients. However, despite the bulk of clinical and epidemiological studies, some grey areas still exist in the understanding of factors related to poor compliance in elderly population. First, assessing regimen complexity on the basis of the number 
of drugs likely misses "intrinsic complexity," ie, the one related to the structure of the therapy. For instance, taking eight different pills corresponding to eight different drugs daily likely is less demanding than taking eight pills three of which are fractionated doses of the same drug. Furthermore, periodically administered drugs, eg, once a week or every other day, are a further source of regimen complexity and, then, a potential risk factor for nonadherence.

In the context of a pharmacosurveillance study, we performed an ancillary study assessing whether and to which extent a previously unexplored measure of regimen complexity, ie, the number of daily administrations of individual drugs, contribute to profile the elderly patient who adheres poorly to the prescribed therapy. We weighed this potential correlate by correcting the statistical model for previously recognized risk factors for poor adherence as well as for the source of informal support. Indeed, we reasoned that provision of care by foreign caregivers might affect the adherence to therapy because of cultural, eg, medication beliefs, and language problems.

\section{Methods}

The present study uses data from a collaborative observational study group, the Pharmacosurveillance in the Elderly Care (PVC) study, based in community and university hospitals located throughout Italy, aimed at surveying drug consumption, prevalence and correlates of potentially inappropriate prescribing, occurrence of adverse drug reactions, and quality of hospital care.

All patients consecutively admitted to the participating wards (11 acute care medical wards and three long-term care/rehabilitation units) from April 1st to June 30th 2007 were asked to participate in the study. After obtaining a written informed consent, a study physician with specific training completed a questionnaire for each patient at admission to hospital and updated it daily. Data recorded included sociodemographic characteristics, medical variables, complete blood count, neuropsychological and physical function variables. ${ }^{20-30}$

Overall, 762 patients were initially screened in the survey period, but $72(9.4 \%)$ refused to participate, which left a final sample of 690 patients. In the present study we used only data collected from the admission to discharge. The study protocol was approved by the Ethical Committee of the Italian National Research Center on Aging (INRCA).

\section{Analytic approach}

The main outcome of our study was the self-reported adherence to drugs taken at home before admission. ${ }^{31}$ For each drug used before the admission, patients were asked the single question about medication adherence: "Have you missed any pills in the last week?" Such a single-question assessment has been reported to have $50 \%$ specificity and $87 \%$ sensitivity for adherence. ${ }^{31}$ In order to improve its diagnostic accuracy, it was supplemented with a latter question about the circumstances of the missed administration: a drug missed for medical reasons, eg, an antidiabetic pill missed because of hypoglycemia, was not considered as nonadherence. For cognitively impaired patients (age- and education-adjusted Mini-Mental State Exam [MMSE] score less than 24), the question was asked to patient's relatives or caregivers. An analytical variable was created to identify patients with self-reported nonadherence for at least one drug taken before admission.

Variables specifically considered in this study were age, gender, years of education, living arrangement, smoking habit, alcohol consumption, type of ward, low self-reported income, need of economic help for health expenses, informal and formal assistance.

Cognitive impairment was ascertained on the basis of MMSE score and was considered as a potential confounder in the analysis. Functional capabilities were rated by basic (BADL) and instrumental activities of daily living (IADL) scales. Patients were categorized as independent (no need of assistance in any activity) or dependent (needs assistance in at least one activity) separately for BADL and IADL. Patients with Geriatric Depression Scale (GDS) score greater than 5 were considered to have depressive symptoms. Comorbidity was rated by Cumulative Illness Rating Scale (CIRS) and two scores were calculated: a) the severity score, which reflects the overall burden of illness, is based on the mean of the ratings across all disease categories, and b) the comorbidity score, which reflects the diversity of illnesses, is the total number of categories in which moderate or severe levels of pathology are noted (range 0 to 13 ).

Diagnoses were coded using the International Classification of Disease 9th Edition - Clinical Modification (ICD9-CM). The most frequent any-listed and first-listed diagnoses were separately considered in the analyses. The overall number of drugs was calculated and considered as a potential correlate of the outcome. Finally, in order to investigate the impact of regimen complexity on medication adherence, the following medication-related measures were considered in the analysis: the use of at least one multiple daily dosing drug (ie, patients who must take the same drug more than once a day), the use of at least one drug taken less than once-a-day (eg, every other day), and the use of subcutaneous or inhaled drug. 


\section{Statistical analysis}

We used unadjusted odds ratios (OR) to compare the sociodemographic and clinical characteristics of patients divided according to the self-reported nonadherence to at least one of the drugs taken at home. Age, gender, and variables significantly distinguishing groups at $p<0.1$ levels in initial analysis were entered into a multivariable logistic regression model to obtain a deconfounded estimate of the correlates of the outcome. The Hosmer and Lemeshow test was used to measure the goodness of fit of the model. ${ }^{32}$ The possibility of interactions between overall number of drugs and measures of medication regimen complexity was also examined. All statistical analyses were performed using SPSS software (version 10.0; SPSS Inc., Chicago, IL).

\section{Results}

We recorded 44 cases of nonadherence to at least one drug, corresponding to a prevalence of $6.4 \%$. Nonadherence was associated with a slightly higher prevalence of cognitive impairment and assistance provided by foreign caregivers with respect to patients reporting regular adherence to all drugs. Among cognitive deficits examined by MMSE, impaired orientation to time (27.3 vs $15.6, \mathrm{p}=0.044)$ and, to a lesser extent, orientation to place $(22.7 \%$ vs $13.5 \%$, $\mathrm{p}=0.087)$, and memory recall $(38.6 \%$ vs $26.0 \%, \mathrm{p}=0.067)$ were more frequent among nonadherent patients. Groups of adherents and nonadherents were comparable as regards age, gender, living arrangement, functional performance, mood, socioeconomic status, and type of admission ward. Renal failure and, to a lesser extent, diabetes mellitus and firstlisted diagnosis of pneumonia were more prevalent among nonadherent patients, while first-listed chronic obstructive pulmonary disease was less frequent among nonadherent patients. The CIRS severity score was higher in nonadherent with respect to adherent patients, while the overall number of drugs taken at home did not distinguish groups. Finally, regimen complexity, ie, taking multiple daily doses of a given drug, was more frequent among nonadherent patients (Table 1).

Summary logistic regression analysis showed that being assisted by foreign caregivers and regimen complexity were significant independent correlates of medication nonadherence (Table 2). The nonsignificant $(p=0.422)$ Hosmer and Lemeshow test was consistent with a satisfactory goodness of fit. Similar results were obtained when impaired orientation and memory recall were considered in the analysis instead of overall MMSE score. Furthermore, there was no interactions between the two medication-related measures (overall number of drugs $>5$ and use of at least one multiple daily dosing drugs) admitted to the final logistic regression model (fully adjusted OR 1.42; 95\% confidence interval [CI] $0.73-2.76 ; p=0.297$ ).

Finally, patients assisted by foreign caregivers were older (age 85 years or more: $28.6 \%$ vs $19.3 \%, p=0.048$ ) and more frequently were female $(71.4 \%$ vs $54.2 \%, \mathrm{p}=0.001)$, and had a greater prevalence of physical (dependence in at least one BADL: $62.9 \%$ vs $25.3 \%, p=0.001$; dependence in three or more IADL $91.4 \%$ vs $68.0 \%, \mathrm{p}=0.001$ ) and cognitive impairment $(71.4 \%$ vs $50.6 \%, p=0.001)$, but had similar need for economic help ( $13.3 \%$ vs $8.9 \%, p=0.154)$, and low self-reported income ( $38.1 \%$ vs $33.5 \%, p=0.361)$ with respect to patients not assisted by foreign caregivers. However, none of these variables was individually correlated with the nonadherence outcome.

\section{Discussion}

The main finding from our study is that in an elderly population regimen complexity, as expressed by the use of at least one multiple daily dose drug, and provision of care by a foreign caregiver are associated with lower adherence to medications, while the overall number of drugs and age are not.

Thus, complex medication regimens may contribute to nonadherence more than the overall number of taken drugs. Conceptually, therapeutic regimen factors, such as multiple daily dosing and pill burden (eg, the necessity to cut tablets) could significantly impact medication adherence, particularly in elderly patients. Surprisingly, only few studies considered regimen factors as potential correlates of nonadherence. ${ }^{14,33}$ On the contrary, polypharmacy per se has been extensively studied in relation to medication adherence and it has been reported to be associated with nonadherence by Vik and colleagues and Lexchin and colleagues, ${ }^{18,19}$ but not in other studies. ${ }^{9,34}$ Patient-related factors, such as vision impairment and/or reduced manual dexterity, and patients' perception of medication importance may contribute to determine the relationship between regimen complexity and nonadherence. ${ }^{35,36}$

The provision of care by a foreign caregiver is a formerly unexplored item in the study of medication nonadherence. Foreign workers of lower socioeconomic status who provide care to more affluent, but frail older adults, represent a universal social phenomenon which poses many difficulties and challenges. These are partially due to very prominent cultural differences between the host culture and the culture of the home care worker, and they are also due to legal, social, and economic differences ingrained in such a care arrangement. ${ }^{37}$ 
Table I Sociodemographic and clinical characteristics of patients divided according to medication adherence

\begin{tabular}{|c|c|c|c|}
\hline & $\begin{array}{l}\text { Adherent } \\
N=646\end{array}$ & $\begin{array}{l}\text { Nonadherent } \\
N=44\end{array}$ & $\begin{array}{l}\text { Unadjusted OR } \\
(95 \% \mathrm{Cl})\end{array}$ \\
\hline \multicolumn{4}{|l|}{ Age } \\
\hline$<75$ & $145(22.4)$ & $12(27.3)$ & 1.0 \\
\hline $75-84$ & $368(57.0)$ & $22(50.0)$ & $0.72(0.35-1.50)$ \\
\hline 85 or more & $133(20.6)$ & $10(22.7)$ & $0.91(0.38-2.17)$ \\
\hline Gender (F) & $370(57.3)$ & $22(50.0)$ & $0.75(0.40-1.37)$ \\
\hline \multicolumn{4}{|l|}{ Years of education } \\
\hline $0-5$ & $498(77.1)$ & $33(75.0)$ & 1.0 \\
\hline $6-8$ & $85(13.2)$ & $5(11.4)$ & $0.88(0.34-2.34)$ \\
\hline $9-13$ & $42(6.5)$ & $4(9.1)$ & $1.44(0.49-4.25)$ \\
\hline$>13$ & $21(3.3)$ & $2(4.5)$ & $1.44(0.32-6.39)$ \\
\hline Living alone & $195(30.2)$ & II (25.0) & $0.77(0.38-1.56)$ \\
\hline Actual smokers & $30(4.6)$ & $3(6.8)$ & $1.50(0.44-5.13)$ \\
\hline Alcohol consumption $>I / 2$ wine equivalent liter & $15(2.3)$ & I (2.3) & $0.99(0.13-7.58)$ \\
\hline Dependency in at least one BADL & $198(30.7)$ & $16(36.4)$ & $1.29(0.68-2.44)$ \\
\hline Dependency in three or more IADL & $46 \mid(7 \mid .4)$ & $33(75.0)$ & $1.20(0.60-2.43)$ \\
\hline Dependency in taking medicine & $323(50.0)$ & $24(54.5)$ & $1.10(0.60-2.03)$ \\
\hline GDS $>5$ & $250(38.7)$ & $18(40.9)$ & $1.10(0.59-2.04)$ \\
\hline MMSE $<24^{*}$ & $342(52.9)$ & $29(65.9)$ & $1.72(0.91-3.27)$ \\
\hline Low self-reported economic income & $221(34.2)$ & $15(34.1)$ & $0.99(0.52-1.89)$ \\
\hline Need of economic help for health expenses & $59(9.1)$ & $7(15.9)$ & $1.88(0.80-4.41)$ \\
\hline \multicolumn{4}{|l|}{ Informal assistance } \\
\hline Spouse & $113(17.5)$ & $8(18.2)$ & $1.05(0.47-2.31)$ \\
\hline Son/daughter* & $210(32.5)$ & $9(20.5)$ & $0.53(0.25-1.10)$ \\
\hline Other relatives & $62(9.6)$ & $7(15.9)$ & $1.78(0.76-4.17)$ \\
\hline Foreign caregiver* & $93(14.4)$ & $12(27.3)$ & $2.23(1.11-4.48)$ \\
\hline None & $34(5.3)$ & I (2.3) & $0.42(0.06-3.13)$ \\
\hline \multicolumn{4}{|l|}{ Formal assistance } \\
\hline Nurse & $96(14.9)$ & $7(15.9)$ & $1.08(0.47-2.50)$ \\
\hline Assistance for daily activities & $136(21.1)$ & $12(27.3)$ & $1.40(0.70-2.80)$ \\
\hline \multicolumn{4}{|l|}{ Type of admission ward } \\
\hline Acute care & $488(75.5)$ & $33(75.0)$ & 1.0 \\
\hline Long-term/rehabilitation care & $158(24.5)$ & II (25.0) & $\mathrm{I} .03(0.5 \mathrm{I}-2.08)$ \\
\hline \multicolumn{4}{|l|}{ Any-listed diagnoses } \\
\hline Hypertension & $442(68.4)$ & $30(68.2)$ & $0.99(0.51-1.90)$ \\
\hline COPD & $25 I(38.9)$ & $15(34.1)$ & $0.81(0.43-1.55)$ \\
\hline Diabetes mellitus* & $158(24.5)$ & $16(36.4)$ & $1.76(0.93-3.35)$ \\
\hline Congestive heart failure & $|4|(2 \mid .8)$ & $8(18.2)$ & $0.80(0.36-1.75)$ \\
\hline Renal failure* & $89(13.8)$ & $12(27.3)$ & $2.35(1.16-4.73)$ \\
\hline \multicolumn{4}{|l|}{ First-listed diagnoses } \\
\hline COPD* & $87(13.5)$ & $\mathrm{I}(2.3)$ & $0.14(0.02-1.10)$ \\
\hline Cerebrovascular disease & $59(9.1)$ & $7(15.9)$ & $1.88(0.80-4.41)$ \\
\hline Congestive heart failure & $58(9.0)$ & $3(6.8)$ & $0.74(0.22-2.47)$ \\
\hline Hypertension & $20(3.1)$ & $\mathrm{I}(2.3)$ & $0.73(0.09-5.55)$ \\
\hline Pneumonia* & $15(2.3)$ & $3(6.8)$ & $3.08(0.90-11.1)$ \\
\hline
\end{tabular}


Table I (Continued)

\begin{tabular}{|c|c|c|c|}
\hline & $\begin{array}{l}\text { Adherent } \\
\mathbf{N}=646\end{array}$ & $\begin{array}{l}\text { Nonadherent } \\
\mathbf{N}=44\end{array}$ & $\begin{array}{l}\text { Unadjusted OR } \\
(95 \% \mathrm{Cl})\end{array}$ \\
\hline \multicolumn{4}{|l|}{ Cumulative illness rating scale } \\
\hline Comorbidity score & $3.8 \pm 1.8$ & $4.2 \pm 2.3$ & $1.12(0.96-1.32)$ \\
\hline Severity score* & $1.8 \pm 0.4$ & $2.0 \pm 0.4$ & $2.22(1.03-4.77)$ \\
\hline \multicolumn{4}{|l|}{ Drugs taken before admission } \\
\hline Overall number of drugs $>5^{*}$ & $287(44.4)$ & $25(56.8)$ & $1.65(0.90-3.05)$ \\
\hline At least one multiple daily dosing drug* & $396(61.3)$ & $37(84.1)$ & $3.34(1.46-7.60)$ \\
\hline At least one drug taken less than once-a-day & $\mid 37(2 \mid .2)$ & II (25.0) & $1.75(0.59-5.15)$ \\
\hline Use of at least one subcutaneous drug & $89(13.8)$ & $6(13.6)$ & $0.99(0.4 \mathrm{I}-2.40)$ \\
\hline Use of at least one inhaled drug & $123(19.0)$ & $7(15.9)$ & $0.80(0.35-1.85)$ \\
\hline
\end{tabular}

Notes: *Marked variables were significantly associated with the outcome at $\mathrm{p}<0.1$ level.

Abbreviations: BADL, basic activities of daily living; CI, confidence interval; COPD, chronic obstructive pulmonary disease; GDS, Geriatric Depression Scale; IADL, instrumental activities of daily living; MMSE, Mini-Mental State Examination; OR, odds ratio.

A cause-effect relationship might explain the observed association between being assisted by foreign caregivers and the outcome: in a study of patients with Alzheimer's disease, caregivers tend to accurately assess their relatives' medication management abilities, and adherence rates were acceptable, but some intervention strategies selected by informal caregivers were not effective in assuring adequate adherence. ${ }^{38}$ Furthermore, cultural barriers may lead foreign caregivers to highlight the positive aspects of traditional (eg, medicinal plant) in contrast with the shortcomings of modern remedies (eg, pharmaceuticals) for health problems. ${ }^{39}$ These findings suggest that educational interventions aimed at improving medication adherence should also target foreign caregivers, especially in countries where formal care is poorly available and foreign caregivers play a major role as health/social care providers. ${ }^{40}$ Unfortunately, the evidence for effective interventions to enhance medication adherence in patients with multiple chronic conditions is weak, and psychosocial interventions are generally absent. ${ }^{41}$ Alternatively, the provision of care by a foreign caregiver could not be causally related to nonadherence, rather it might simply target the patient at risk of nonadherence. Seemingly contradicting this interpretation is the fact that factors profiling the patient assisted by foreign caregivers (eg, older age, cognitive and physical impairment) were individually unrelated to the outcome. However, it cannot be excluded that these "frailty" variables, taken together, but not individually, qualify as a cumulative risk factor. Additionally, the high prevalence of cognitive impairment and dependency in IADL might result in a ceiling effect preventing any correlation with the outcome.

Age did not correlate with poor compliance. This finding confirms several observations in different populations. ${ }^{10,42-46}$
However, variant results deserve consideration: in two hypertensive populations, age has been identified as a risk factor for ${ }^{9}$ or a protective factor against poor compliance. ${ }^{8}$ Also in rheumatoid arthritis patients, older age has been associated with better compliance, whereas a busy lifestyle contributed significantly to the clinical profile of a nonadherent patient. ${ }^{47}$ Similarly, younger age was associated with lower adherence in a population of Medicaid beneficiaries with congestive heart failure, ${ }^{48}$ and in patients with depression. ${ }^{49}$ Differences in the methods used to measure adherence, in the study populations and in the set of collected potential correlates of nonadherence likely account for discrepancies. Overall, supporting the prevailing evidence, our results state against any association between age and nonadherence.

At variance from data reported by Wamala and colleagues,${ }^{16}$ no social indicator correlated with nonadherence in our population. This might depend upon the age of our patients: very old people are burdened with several medical conditions which likely overcome the effect of social variables on the risk of nonadherence. Furthermore, the tight family ties in Italy likely mitigated the impact of social disparities on the outcome. Indeed, more than half of the enrolled patients were assisted by and $68.3 \%$ lived with spouse, sons or other relatives in our study.

Limitations deserve to be cited. First, we defined nonadherence on the basis of a single question assessment, which might underestimate the prevalence of the outcome in comparison with other studies. ${ }^{5,8-15}$ More elaborate questionnaires ${ }^{50,51}$ may estimate more accurately the prevalence of the outcome. However, such an approach would have increased the burden of the interview for patients and their relatives/ caregivers in the context of an extensive data collection. 
Table 2 Summary logistic regression of selected variables to medication nonadherence

\begin{tabular}{lll}
\hline & OR & $95 \% \mathbf{C l}$ \\
\hline Age & & \\
$\quad<75$ & 1.0 & \\
$75-84$ & 0.57 & $0.26-1.24$ \\
85 or more & 0.61 & $0.24-1.58$ \\
Gender (F) & 0.66 & $0.34-1.30$ \\
MMSE $<24$ & 1.33 & $0.67-2.65$ \\
Informal assistance & & \\
$\quad$ Son/daughter & 0.86 & $0.35-2.09$ \\
$\quad$ Foreign caregiver & 2.17 & $1.02-4.63$ \\
Any-listed diagnoses & & \\
$\quad$ Diabetes mellitus & 1.17 & $0.58-2.36$ \\
$\quad$ Renal failure & 1.94 & $0.88-4.27$ \\
First-listed diagnoses & & \\
$\quad$ COPD & 0.16 & $0.02-1.22$ \\
Pneumonia & 3.54 & $0.88-14.2$ \\
Cumulative illness rating scale severity score & 1.38 & $0.56-3.40$ \\
Drugs taken before admission & & \\
$\quad$ Overall number of drugs $>5$ & 1.05 & $0.52-2.10$ \\
At least one multiple daily dosing drug & 2.99 & $1.24-7.17$ \\
\hline
\end{tabular}

Notes: Hosmer and Lemeshow Chi-square $=8.1 \mathrm{I} 3 ; \mathrm{df}=8 ; \mathrm{p}=0.422$.

Abbreviations: $\mathrm{Cl}$, confidence interval; $\mathrm{COPD}$, chronic obstructive pulmonary disease; MMSE, Mini-Mental State Examination; OR, odds ratio.

Furthermore, a single question about medication adherence has been considered a simple and effective method to identify nonadherent patients also in other studies. ${ }^{52-54}$ Second, a more detailed neuropsychological assessment of functions relevant to the outcome (eg, memory assessment) might have disclosed significant association between cognitive status and nonadherence. Indeed, recent evidence suggests that memory impairment may worsen medication management abilities, thus contributing to unintentional medication nonadherence. ${ }^{55}$ Third, our dataset did not allow to investigate the possible interaction between taking the same drug more than once a day and taking many drugs at different times during the day. Fourth, we did not collect information on education, linguistic skill, and other characteristics of foreign caregivers, which limits our interpretation of the positive association between being assisted by a foreign caregiver and poor adherence. Finally, our population was enrolled in the hospital and therefore our results might not apply to people who do not experience a hospital admission.

In conclusion, our results suggest that multiple daily dosing might add to the number of prescribed drugs as an indicator of regimen complexity affecting adherence. Thus, a strategy limiting multiple daily dosing, eg, by using some extended release drugs, might be worthy of testing. Most important, components of regimen complexity affecting adherence and their interaction with other factors, such as the source of care, should be carefully investigated. Collaterally, the relationship between poor adherence and provision of care by a foreign caregiver suggests that strategies promoting medication adherence by dedicated teaching programs are desirable. Finally and first of all, a systematic screening of nonadherence should be part of the medical approach to geriatric patients.

\section{Acknowledgments}

The PVC study was partially supported by a grant from the Italian Ministry of Health (RF-INR-2005-127640). All authors report no conflicts of interest in this work.

\section{List of participating centers}

Coordinating center: A. Corsonello, M. Lucchetti, M. Di Muzio, G. Gioia Lobbia, S. Giunta, S. Garasto, C. Carbone, C. Greco, P. Fabbietti, R. Firmani, M. Nacciariti, F. Lattanzio (INRCA, Ancona and Cosenza, Italy). Clinical centers: INRCA Ancona - G. Cadeddu, R. Ganzetti; INRCA Appignano - E. Giannandrea, A. Marrocchi, D. Giannandrea; INRCA Casatenovo - E. Guffanti, E. Marchi, P. Castellotti, D. Bonardi, A. Limonta; University of Chieti - A. Di Iorio, M. Abate, A. Leoncavallo, F. Di Giambattista; INRCA Cosenza - B. Mazzei, L. Pranno, C. Zottola, E. Feraco, A. Madeo, R. Gallo, G. Nicotera, P. Scarpelli, A. Tarsitano, A. Gervino; INRCA Fermo - D. Postacchini, G. Cruciani, R. Brunelli, F. Sorvillo, M. Francavilla, R.L. Marzullo, C. Giuli; University of Ferrara - S. Volpato, C. Maraldi, M. Cavalieri, G. Guerra, F. Sioulis, L. Testoni, S. Postorivo, R. Fellin; University of Messina - F. Corica, C. Nicita Mauro, G. Basile, V. Nicita Mauro; University of Modena- C. Mussi, R. Scotto, G. Salvioli; INRCA Roma - A. Scuteri, L. Masci; University Campus Biomedico, Roma - C. Pedone, F. M. Serino, R. Antonelli Incalzi.

\section{References}

1. Dorz S, Lazzarini L, Cattelan A, et al. Evaluation of adherence to antiretroviral therapy in Italian HIV patients. AIDS Patient Care STDS. 2003;17:33-41.

2. Volmink J, Garner P. Systematic review of randomised controlled trials of strategies to promote adherence to tuberculosis treatment. BMJ. 1997;315:1403-1406.

3. Mallion J, Dutrey-Dupagne C, Vaur L, et al. Benefits of electronic pillboxes in evaluating treatment compliance of patients with mild to moderate hypertension. J Hypertens. 1996;14:137-144.

4. Benner J, Glynn R, Mogun H, et al. Long-term persistence in use of statin therapy in elderly patients. JAMA. 2002;288:455-461. 
5. Bezie Y, Molina M, Hernandez N, et al. Therapeutic compliance: a prospective analysis of various factors involved in the adherence rate in type 2 diabetes. Diabetes Metab. 2006;32:611-616.

6. Vrijens B, Vincze G, Kristanto P, et al. Adherence to prescribed antihypertensive drug treatments: longitudinal study of electronically compiled dosing histories. BMJ. 2008;336:1114-1117.

7. Ho PM, Rumsfeld JS, Masoudi FA, et al. Effect of medication nonadherence on hospitalization and mortality among patients with diabetes mellitus. Arch Intern Med. 2006;166:1836-1841.

8. Morrell RW, Park DC, Kidder DP, et al. Adherence to antihypertensive medications across the life span. Gerontologist. 1997;37:609-619.

9. Siegel D, Lopez J, Meier J. Antihypertensive medication adherence in the Department of Veterans Affairs. Am J Med. 2007;120:26-32.

10. Gazmararian JA, Kripalani S, Miller MJ, et al. Factors associated with medication refill adherence in cardiovascular-related diseases: a focus on health literacy. J Gen Intern Med. 2006;21:1215-1221.

11. Inkster ME, Donnan PT, MacDonald TM, Sullivan FM, Fahey T. Adherence to antihypertensive medication and association with patient and practice factors. J Hum Hypertens. 2006;20:295-297.

12. Johnell K, Råstam L, Lithman T, et al. Low adherence with antihypertensives in actual practice: the association with social participation - a multilevel analysis. BMC Public Health. 2005;5:17.

13. Wang PS, Bohn RL, Knight E, et al. Noncompliance with antihypertensive medications: the impact of depressive symptoms and psychosocial factors. J Gen Intern Med. 2002;17:504-511.

14. Lam PW, Lum CM, Leung MF. Drug non-adherence and associated risk factors among Chinese geriatric patients in Hong Kong. Hong Kong Med J. 2007;13:284-292.

15. Wang PS, Avorn J, Brookhart MA, et al. Effects of noncardiovascular comorbidities on antihypertensive use in elderly hypertensives. Hypertension. 2005;46:273-279.

16. Wamala S, Merlo J, Bostrom G, et al. Socioeconomic disadvantage and primary non-adherence with medication in Sweden. Int J Qual Health Care. 2007;19:134-140.

17. Kammerer J, Garry G, Hartigan M, et al. Adherence in patients on dialysis: strategies for success. Nephrol Nurs J. 2007;34:479-486.

18. Vik SA, Maxwell CJ, Hogan DB. Measurement, correlates and health outcomes of medication adherence among seniors. Ann Pharmacother. 2004;38:303-312.

19. Lexchin J, Grootendorst P. Effects of prescription drug user fees on drug and health services use and on health status in vulnerable populations: a systematic review of the evidence. Int $J$ Health Serv. 2004:34:101-122.

20. Carosella L, Pahor M, Pedone C, et al. Pharmacosurveillance in hospitalized patients in Italy: study design of the Gruppo Italiano di Farmacovigilanza nell'Anziano' (GIFA). Pharmacol Res. 1999;40:287-295.

21. Pahor M, Chrischilles EA, Guralnik JM, et al. Drug data coding and analysis in epidemiologic studies. Eur J Epidemiol. 1994;10:405-411.

22. National Center for Health Statistics. International classification of diseases, ninth revision, clinical modifications. Washington, DC: Public Health Service, Health Care Financing Administration; 1980.

23. Folstein MF, Folstein SE, McHigh PR. "Mini Mental State": a practical method for grading the cognitive state of patients for the clinician. J Psychiatr Res. 1975;12:189-198.

24. Lesher EL, Berryhill JS. Validation of the Geriatric Depression ScaleShort Form among inpatients. J Clin Psychol. 1994;50:256-260.

25. Katz S, Ford AB, Moskowitz RW, et al. Studies of illness in aged: the index of ADL, a standardized measure of biological and psychosocial function. JAMA. 1963;185:94-106.

26. Lawton MP, Brody EM. Assessment of older people: self-maintaining and instrumental activities of daily living. Gerontologist. 1969;9:179-186.

27. Antonelli Incalzi R, Corsonello A, Pedone C, et al. Construct validity of activities of daily living scale: a clue to distinguish the disabling effects of COPD and congestive heart failure. Chest. 2005;127:830-838.

28. Conwell Y, Forbes NT, Cox C, et al. Validation of a measure of physical illness burden at autopsy: the Cumulative Illness Rating Scale. $J$ Am Geriatr Soc. 1993;41:38-41.
29. World Health Organization. International drug monitoring: The role of the hospital. WHO Technical Report Series No. 425. Geneva, Switzerland: World Health Organization; 1969.

30. Naranjo CA, Busto U, Sellers EM, et al. A method for estimating the probability of adverse drug reactions. Clin Pharmacol Ther. 1981;30:239-245.

31. Haynes RB, McDonald HP, Garg AX. Helping patients follow prescribed treatment: clinical applications. JAMA. 2002;288:2880-2883.

32. Hosmer D, Lemeshow S. Applied logistic regression. New York, NY: John Wiley and Son; 1989.

33. Ingersoll KS, Cohen J. The impact of medication regimen factors on adherence to chronic treatment: a review of literature. J Behav Med. 2008;31:213-224.

34. Shalansky SJ, Levy AR. Effect of number of medications on cardiovascular therapy adherence. Ann Pharmacother. 2002;36:1532-1539.

35. Nikolaus T, Kruse W, Bach M, Specht-Leible N, Oster P, Schlierf G. Elderly patients' problems with medication. An in-hospital and followup study. Eur J Clin Pharmacol. 1996;49:255-259.

36. Lau DT, Briesacher BA, Mercaldo ND, et al. Older patients' perceptions of medication importance and worth: an exploratory pilot study. Drugs Aging. 2008;25:1061-1075.

37. Ayalon L, Kaniel M, Rosenberg L. Social workers' perspectives on care arrangements between vulnerable elders and foreign home care workers: lessons from Israeli/Filipino caregiving arrangements. Home Health Care Serv Q. 2008;27(2):121-142.

38. Cotrell V, Wild K, Bader T. Medication management and adherence among cognitively impaired older adults. J Gerontol Soc Work. 2006;47(3-4):31-46.

39. Wayland C. The failure of pharmaceuticals and the power of plants: medicinal discourse as a critique of modernity in the Amazon. Soc Sci Med. 2004;58:2409-2419.

40. Carpenter GI. Aging in the United Kingdom and Europe - a snapshot of the future? J Am Geriatr Soc. 2005;53(9 Suppl):S310-313.

41. Williams A, Manias E, Walker R. Interventions to improve medication adherence in people with multiple chronic conditions: a systematic review. J Adv Nurs. 2008;63:132-143.

42. Chapman RH, Petrilla AA, Benner JS, Schwartz JS, Tang SS. Predictors of adherence to concomitant antihypertensive and lipid-lowering medications in older adults: a retrospective, cohort study. Drugs Aging. 2008;25:885-892.

43. Wu JR, Moser DK, Chung ML, Lennie TA. Predictors of medication adherence using a multidimensional adherence model in patients with heart failure. J Card Fail. 2008;14(7):603-614.

44. Odegard PS, Gray SL. Barriers to medication adherence in poorly controlled diabetes mellitus. Diabetes Educ. 2008;34(4):692-697.

45. Molloy GJ, Perkins-Porras L, Strike PC, Steptoe A. Social networks and partner stress as predictors of adherence to medication, rehabilitation attendance, and quality of life following acute coronary syndrome. Health Psychol. 2008;27:52-58.

46. Carr AJ, Thompson PW, Cooper C. Factors associated with adherence and persistence to bisphosphonate therapy in osteoporosis: a crosssectional survey. Osteoporos Int. 2006;17:1638-1644.

47. Park DC, Hertzog C, Leventhal H, et al. Medication adherence in rheumatoid arthritis patients: older is wiser. $J$ Am Geriatr Soc. 1999;47:172-183.

48. Bagchi AD, Esposito D, Kim M, Verdier J, Bencio D. Utilization of, and adherence to, drug therapy among medicaid beneficiaries with congestive heart failure. Clin Ther. 2007;29:1771-1783.

49. Bambauer KZ, Soumerai SB, Adams AS, Zhang F, Ross-Degnan D. Provider and patient characteristics associated with antidepressant nonadherence: the impact of provider specialty. J Clin Psychiatry. 2007;68(6):867-873.

50. Moriski DE, Green LW, Levine DM. Concurrent and predictive validity of a self-reported measure of medication adherence. Med Care. 1986;24:67-74.

51. Andrade SE, Kahler KH, Frech F, et al. Methods for evaluation of medication adherence and persistence using automated databases. Pharmacoepidemiol Drug Saf. 2006;15:565-574. 
52. Haynes RB, McDonald HP, Garg AX. Helping patients follow prescribed treatment: clinical applications. JAMA. 2002;288(22): 2880-2883.

53. Nelson MR, Reid CM, Ryan P, et al. Self-reported adherence with medication and cardiovascular disease outcomes in the Second Australian National Blood Pressure Study (ANBP2). Med J Aust. 2006;185:487-489.
54. Gehi AK, Ali S, Na B, et al. Self-reported medication adherence and cardiovascular events in patients with stable coronary heart disease: the heart and soul study. Arch Intern Med. 2007;167:1798-1803.

55. Depp CA, Cain AE, Palmer BW, et al. Assessment of medication management ability in middle-aged and older adults with bipolar disorder. J Clin Psychopharmacol. 2008;28:225-229. 